This is the author's final, peer-reviewed manuscript as accepted for publication. The publisher-formatted version may be available through the publisher's web site or your institution's library.

\title{
From firm-controlled to consumer-contributed: consumer co- production of personal media marketing communication
}

Todd J. Bacile, Christine Ye, Esther Swilley

\section{How to cite this manuscript}

If you make reference to this version of the manuscript, use the following information:

Bacile, T. J., Ye, C., \& Swilley, E. (2014). From firm-controlled to consumer-contributed: Consumer co-production of personal media marketing communication. Retrieved from http://krex.ksu.edu.

\section{Published Version Information}

Citation: Bacile, T. J., Ye, C., \& Swilley, E. (2014). From firm-controlled to consumercontributed: Consumer co-production of personal media marketing communication. Journal of Interactive Marketing, 28(2), 117-133.

Copyright: @ 2013 Direct Marketing Educational Foundation, Inc., dba Marketing EDGE. Published by Elsevier.

Digital Object Identifier (DOI): doi:10.1016/j.intmar.2013.12.001

Publisher's Link: http://www.sciencedirect.com/science/article/pii/S1094996813000637

This item was retrieved from the K-State Research Exchange (K-REx), the institutional repository of Kansas State University. K-REx is available at http://krex.ksu.edu 


\title{
From Firm-Controlled to Consumer-Contributed: Consumer Co-Production of Personal Media Marketing Communication
}

\author{
Todd J. Bacile \\ Loyola University New Orleans, Joseph A. Butt, S.J., College of Business, 6363 St. Charles \\ Avenue, New Orleans, LA 70118, USA
}

Christine Ye

Westminster College, Bill and Vieve Gore School of Business, 1840 South 1300 East, Salt Lake City, UT 84105, USA

Esther Swilley

Kansas State University, College of Business Administration, Department of Marketing, 201A Calvin Hall, Manhattan, KS 66506-0506, USA 


\begin{abstract}
Fueled by the sociocultural shift from firm-controlled to consumer-contributed media, the researchers explore the idea of adapting a co-production strategy from service marketing to marketing communication sent to personal media. Eleven field experiments with firms, along with a structural model tested on survey data, provide empirical evidence supporting a coproduction approach applied as a communication strategy in the context of a text message mobile coupon marketing campaign. The results demonstrate a co-produced direct marketing communication strategy increases attitude toward the communication, purchase intent, and purchase activity, while also acting as a risk-reducing mechanism. Furthermore, perceived customization of the communication interacts strongly with risk perception and marginally with coupon proneness as related to attitude toward the communication when marketers enter the world of consumers' personal media. A push versus pull framework and a co-produced communication framework are put forth to suggest various areas marketers can make available for consumers to co-produce in a marketing communication exchange.
\end{abstract}

"[C] ustomers in contexts other than those traditionally considered service interfaces are in reality involved in service-like processes.” - Christian Grönroos (2006, p. 329)

\title{
Introduction
}

The rising importance and prevalence of personal media on mobile phones are creating new opportunities for marketers, but a lack of strategies in these communication channels is surfacing (Hennig-Thurau et al. 2010). A key differentiating element tempering firms' success is personal media are more important to consumers than mass media, causing many consumers to elect not to receive intrusive marketing messages and to become less tolerant of irrelevant messages. The prominence of identifying effective strategies is amplified by the upsurge in direct marketing communication, hereafter referred to as communication, sent to such media. For example, spending for communication sent to mobile and social media will reach $\$ 8$ billion and \$5 billion, respectively, by 2016 (VanBoskirk 2011). 
For our purposes, personal media refers to highly individualized and important communication tools primarily for interpersonal communication, such as the telephone, chat, text messaging, and social media through a mobile device (Lüders 2008). The mobile phone is the platform extraordinaire for such media as it is personal and drives media use. Both the individual nature and importance of personal media within consumers' lives are apparent (Hennig-Thurau et al. 2010). As such, psychological barriers exist which firms must overcome when sending communication through personal media, such as risk perception of a negative outcome including privacy concerns, irrelevant messages, message volume, and intrusiveness (Deighton and Kornfeld 2009; Sultan, Rohm, and Gao 2009). Currently, the primary strategy firms use to reduce risk perception of a negative outcome is to grant consumers the right to opt-in and opt-out (i.e. give or remove permission) to receive communication sent to personal media (Barwise and Strong 2002). However, other than these two all-or-nothing inputs, firms typically do not allow consumers to participate in further decision making inputs into the communication process. This lack of consumer participation is reminiscent of traditional mass media where the firm views the consumer as a passive audience member (Wind and Rangaswamy 2001). Aside from opt-in or opt-out decisions, in both mass and personal media, the time, frequency, subject, and type of communication are generally decided by marketers. This consistency between mass and personal media is surprising, considering labels such as "customized" and "personalized" that often differentiate personal media from mass media (Shankar and Balasubramanian 2009).

The current paper suggests firms view personal media communication as an interactive process with consumers in contrast to the classic one-way marketing communication model. This proposed type of exchange positions personal media communication similar to the modern viewpoint of service as interactive firm-consumer processes. Various service philosophies such 
as service logic (Grönroos 2006), service-dominant logic (Vargo and Lusch 2004), and unified services theory (Sampson and Froehle 2006) each discuss consumers providing inputs to firms during interactive processes as co-producing activities central to service exchange. An example of such inputs includes consumers specifying their desired preferences within a service offering. Thus, the purpose of this research, and one hypothesized to improve firm outcomes and consumer psychological and behavioral responses, is to empirically assess if a service strategy such as co-production can be adapted as a marketing communication strategy in personal media.

This study contributes to marketing theory and practice in a number of ways. The theoretical contribution of this manuscript is to extend the domain of service to marketing communication. Personal media communication is becoming service-like in nature. Technology has rendered complex formerly simple dissemination of firm communication. Marketing communication is evolving from a one-way, firm-controlled message subject with a simple effort allocation approach, to a two-way, consumer participatory service-like exchange merging firmconsumer processes. Firms should engage consumers by enabling the co-production of some aspect of the communication process. This is a unique perspective not present within emerging models of direct marketing via personal media (e.g. Deighton and Kornfeld 2009; Shankar et al. 2010; Sultan, Rohm, and Gao 2009). As shown in two studies, the extension of marketing communication theory is possible with the application of this service strategy. The authors offer a push versus pull framework and a personal media co-production framework discussing many characteristics of these communication exchanges that are ideally suited to co-produce.

The empirical contribution of the current research demonstrates large improvements in the effectiveness of promotional communication in the form of a text message mobile coupon via a series of field experiments in Study 1. The results imply co-producing communication 
improves consumer response. Using survey data with structural equation modeling then uncovers mechanisms underlying this effectiveness in Study 2, which hones in on perceived customization as the key driver behind enhanced response to a firm's mobile coupon promotion. Risk perception is present when communication is sent to personal media, and we show a coproduction strategy attenuates this risk. In addition to acting as a risk-reducing mechanism, results suggest co-production improves attitude toward the communication and purchase intent, with perceived customization of the communication interacting strongly with risk perception and marginally with coupon proneness as each relates to attitude toward the communication. The remainder of this paper discusses communication theory and the theoretical development on the ways in which personal media communication is evolving toward a service-like offering. The hypotheses and conceptual model are formulated and assessed in two studies, followed by a discussion of all findings, theoretical implications, and managerial ramifications.

\section{Theoretical Development}

\section{Communication Theory}

Marketers using traditional mass media to disseminate communication typically follow a process consistent with the transmission model of mass communication (Shannon and Weaver 1949). The basis of this model is information processing and communication theory. These steps within the communication process have been adapted to various communication models, yet the core steps remain the same. Communication is a process, where a breakdown in any step disrupts the entire process. A source creates a message by encoding it into a format conducive for a particular medium. The message is sent via a medium, upon which a receiver must decode the message. Encoding the proper message containing information of interest to a receiver and using 
the correct medium should result in optimal communication between two parties. Passive feedback is generated back to the source after receiving a message (i.e. ignoring a message, remembering a message for later use, making a purchase, or telling others) with limited ability for specific direct communication in response to a message (i.e. active feedback). This overarching control over one-way communication is consistent with the political economy of communication theory (Graham 2007; Innis 1942), which posits that a select few controlling entities, such as owners of communication networks and resourceful brands, attempt to persuade the thoughts and actions of consumers because these entities have the power to do so. Mass media marketing communication is based upon this format of one-way communication.

In large part, mass media marketing communication is sub-optimal and described as “wasteful marketing” (Sheth and Sisodia 2006, p. 7). Mass media's ineffectiveness, coupled with the interactive nature of emergent technologies such as personal media, are causing new paradigms to materialize (Deighton and Kornfeld 2009; Shankar et al. 2010; Sultan, Rohm, and Gao 2009). Yet, such newer frameworks are still derived from mass media's centrally managed philosophy. Emerging frameworks are adapting mass media's need to infer and exploit consumers' information to craft communication in a manipulative or intrusive manner. As an example, Deighton and Kornfeld (2009) offer up multiple consumer roles emerging across a twoby-two linear matrix: Accessibility $\leftrightarrow$ Identity and Information $\leftrightarrow$ Meaning. Within this matrix the researchers posit that the most attractive form of interactivity is a higher degree of knowing an individual consumer's identity and a higher degree of brand meaning in specific contexts for individual consumers. Largely absent from this framework is a consumer role with high degrees of identity and meaning, while avoiding direct marketing's need to infer, exploit, or compete against consumer-provided primary or secondary information. 
This paper suggests that firms enabling consumers to actively participate in some aspect of the communication process prior to receiving a marketing message via personal media avoids the need for firms to infer or exploit consumer information. The difference from mass media's communication model is a consumer participating (i.e. co-producing) by providing preferences to a firm prior to sending marketing messages to a consumer. Firm-consumer participation in this context is similar to the provision of service.

\section{Co-Production and A Service Orientation}

A consistent theme across many service philosophies is co-production, which is defined as consumers participating with firms in at least one interactive decision-making process prior to the usage of a good or service (Etgar 2008; Grönroos 2006). In service exchange, the co-creation of value is always present, but co-production may vary from none at all to a high degree depending on the level of interactive firm-consumer processes prior to usage (Vargo and Lusch 2008). Firms offer co-production opportunities by not only enabling consumers to participate in labor, but also using customer-provided information, such as consumers providing preferred characteristics and attributes within an offering (Grönroos 2006; Sampson and Froehle 2006). Etgar (2008, p. 97) states "co-production is an explicit result of decision making by consumers reflecting their own preferences." Consistent with this rationale, researchers use customization to represent or establish a direct link with co-production (Auh et al. 2007; Etgar 2008).

Co-production of some aspect of the communication process occurs when a consumer decides a marketing message's delivery time, frequency, recipient, subject, format, preferred media channel, or any other message characteristic prior to receiving a marketing communication. Consumers providing preferences to firms for any of these characteristics are in 
effect co-producing the communication process. Whereas mass media limit a consumer as an inactive participant, co-producing the communication process in personal media enables active participation of a consumer to decide some aspect of a communication prior to receiving. This communication-based view of co-production is consistent with Etgar's (2008) service-based view of co-production. Positing the domain of co-production as applicable to personal media marketing communication is a logical evolutionary path when one considers the progression toward the modern understanding of service.

The emergence of a service orientation is expanding the purview of service from earlier connotations of an intangible act, such as a gas station attendant pumping fuel, to firm-consumer interactions, exchanges, and processes. The modern definition of service is the application of interactive firm-consumer processes to create value. This definition captures the essence across many service philosophies, including service logic (Grönroos 2006), service-dominant logic (Vargo and Lusch 2004), and unified services theory (Sampson and Froehle 2006).

The Nordic school's service logic distinguishes a service from a physical good by proposing that the former is a firm-consumer process exchange (Grönroos 2006). Services are processes, rather than objects for economic, transactional exchange; and these firm-consumer processes take place in interactions. Hence, service logic defines service as processes which aim to solve consumers' problems through firm-consumer interactions, be it in-person or technologymediated. Consumers co-producing service processes are co-creators of value.

Using similar reasoning, service-dominant logic implies all firms are service providers, with service being the fundamental basis of exchange (Vargo and Lusch 2004; 2008). Servicedominant logic suggests a shift is occurring, where intangible resources and co-creation of value through service provision are replacing the traditional view of marketing based on the economic 
exchange of goods. Service-dominant logic defines service as the application of specialized processes by one entity to benefit another entity. Firms use such processes with consumers to cocreate value. A distinct component of value co-creation is co-production (Vargo and Lusch 2008). Service always co-creates value, yet involving consumers as co-producers is optional.

Unified services theory's view of service is consistent with service logic and servicedominant logic. Unified services theory differentiates service processes from non-service processes by involving a consumer to provide specific inputs into the production of service (Sampson and Froehle 2006). Production processes that do not require specific consumer inputs are managed differently, such as mass manufacturing. Groups of consumers contribute ideas and market research within a manufacturing context, yet their direct inputs are absent (i.e. a specific product is not produced for a specific consumer based on inputs). Co-production is a method for a consumer to provide specific inputs into the service production process.

Associating co-production with promotional communication processes separate and distinct from product offerings may seem incongruent. Research illustrates this incongruence by often focusing on co-production of a good or service product (e.g. Auh et al. 2007; Bendapudi and Leone 2003). However, co-production is applicable to underlying process activities and interactions to exchange information that will ultimately co-create value (Grönroos 2006). Such processes can produce accurate and useful personal media communication, leading to positive outcomes for firms and consumers (Duncan and Moriarty 2006).

Co-production of some aspect of the communication process by enabling consumers to participate by providing preferences supports the notion that communication exchange is a firmconsumer encounter becoming process-like (Payne, Storbacka, and Frow 2008). Direct marketing communication sent to personal media is now a construction process based on mutual 
understanding between firms and consumers (Firat and Dholakia 2006). This recognition of communication as a process-like firm-consumer exchange encounter is similar to the modern view of a service orientation. Within a service orientation marketers adopt a participatory role in communication iterations with consumers to promote learning, create accurate offers, build relationships, and co-create value (Ballantyne and Varey 2006; Duncan and Moriarty 2006).

We believe that merging a co-production strategy to personal media communication is consistent with the co-production consumer engagement model (Etgar 2008). This model identifies situations where firms should involve consumers in co-production and customization. The first two stages (co-production antecedent conditions and consumer motivations to coproduce) are useful to assess if co-producing personal media communication is a viable strategy. Ideal antecedent conditions in Stage 1 include assessing technological, economic, and cultural factors. These conditions are prevalent in personal media, as the increasing number of electronic touch points creates easy to use and low cost methods for consumers to interact with firms (Prahalad and Ramaswamy 2004). Higher per capita incomes in mature markets tend to have cultures that place a high value on customization, increasing the likelihood of consumers preferring to co-produce (Etgar 2008).

The second stage, consumer motivation to co-produce in personal media, is driven by one particular psychological factor - importance. When tasks, situations, decisions, or encounters are perceived to be highly important, the integrative control model (Brehm 1972; Wortman and Brehm 1975) posits people need control, or more accurately, perceived control. Important situations amplify the necessity to avoid negative outcomes. The concept of importance is relevant to personal media given that consumers place a high degree of importance upon these channels. Perceived control enables consumers to tolerate the risk of potentially negative 
outcomes (Lee and Allaway 2002). To achieve higher perceived control consumers use coproduction and customization (Auh et al. 2007; Bateson 1985). One caveat of co-production and customization is that a positive manifestation may not result. Complexity and uncertainty can occur when a consumer is beset with information overload or unsure of the best options (Huffman and Kahn 1998). However, customization does not produce these negative occurrences when a consumer is conversant in choice options that best meet their specific needs (Godek, Yates, and Yoon 2002).

The present paper conducts two studies to assess some of the benefits of a personal media co-production strategy for firms. With the presence of the antecedent conditions and motivation to co-produce, we posit co-producing some aspect of the communication process will influence purchase behavior in Study 1. We support this position by drawing from extant research in coproducing goods and services, and applying this logic to co-producing communication. Coproducing a good or a service creates an offering with specific options meeting individual needs of a consumer, making it more likely a purchase will occur (Wind and Rangaswamy 2001). It is also possible the mere act of involvement in creating an offering is a source of value, which ultimately increases purchase behavior (Auh et al. 2007). In either case, co-production functions as a powerful strategy to improve consumer purchase behavior which has yet to be assessed in the domain of marketing communication. We propose purchase redemption, which is a response to a communication resulting in a purchase, will be higher for consumers who co-produce some aspect of the communication process versus non-co-producers.

H1: Purchase redemption will be higher for consumers co-producing some aspect of the communication process within personal media compared to consumers who do not co-produce. 


\section{Study 1}

Study 1 was designed to test $\mathrm{H} 1$ under actual market conditions. A mobile marketing firm agreed to a field experiment to compare purchase redemption of consumers in two groups: those who co-produce some aspect of the personal media communication process versus those who do not co-produce. Among personal media consumers use daily, none are more important than mobile phones (Hennig-Thurau et al. 2010). The most popular form of direct marketing communication sent to mobile phones are text message mobile coupons (m-coupons) containing a discount offer and/or promotional information (Dickinger and Kleijnen 2008; Shankar and Balasubramanian 2009). The particular feature of the m-coupon to be co-produced in Study 1 is the delivery time of the communication. Delivery time is an ideal feature to investigate in the current context since the success of m-coupon campaigns highly depend on messages' time of delivery (Bacile and Goldsmith 2011; Barwise and Strong 2002). Mobile devices offer users value-for-time and afford consumers the opportunity to receive information anytime and anywhere (Clarke 2001). By-enabling consumers to decide their preferred delivery time, in effect consumers are co-producing the communication process, since this type of digital communication does not exist until consumers receive the message. This operationalization aligns with the core idea of co-production, "which may take place within the production process which precedes the usage stage," (Etgar 2008, p. 98) .

\section{Field Setting and Sample}

Four casual restaurants in two cities with populations between 100,000 and 500,000 in the southeastern United States agreed to participate. Restaurants were the industry of choice due to ecological validity based on two reasons: restaurants frequently make use of coupons in marketing promotions and m-coupons are anticipated to be heavily used by the restaurant 
industry (eMarketer 2010). A total of 11 experiments were conducted. The restaurants used promotional communication in print media, signage in their surrounding areas, Web sites, and retail signage outside and inside the restaurants asking consumers to opt-in to a new text message promotion. The advertisements directed consumers to each restaurant's Web site, where a Web form was used by consumers to enter their mobile phone number to opt-in. The Web page housing the opt-in form randomly presented one of two possible forms to consumers. This insured random assignment to each of the two groups. On one form the consumers were only required to opt-in by entering their mobile phone number, thus representing a control group of non-co-production subjects. In contrast, the other form contained two additional fields consumers used to select the day of the week and time of the day to receive an m-coupon, thus representing the treatment group of co-production subjects.

A field study can limit the control of other factors that may influence results, such as one group having subjects who are more or less technology ready than the other group. However, the

field experiment randomly assigned subjects to each group. The average control group size $(\mathrm{n}=$ $116)$ and average treatment group size $(\mathrm{n}=119)$ in each of the 11 field experiments were sufficiently large to cancel the main effects of uncontrolled factors.

\section{Measure}

The number of purchase redemptions produced by the m-coupon (i.e. the redemption rate) was assessed. Each consumer in the treatment and control group was sent an m-coupon with a code number indicating to the restaurant a consumer was redeeming either a co-produced or non-co-produced m-coupon. At the time of purchase the text message was shown to the cashier 
who recorded the code. The use of two unique coupon codes made it easy to compare the number of purchase redemptions in the treatment group compared to the control group.

\section{Analysis and Results}

In each of the 11 experiments the same m-coupon wording and discount amount was issued to consumers in each of the two groups. For example, in one experiment both groups received an m-coupon good for $25 \%$ off a meal; however, the treatment group's m-coupons were sent on the day and time as specified by each consumer. The range of discount amount offered across each of the 11 experiments was $20 \%-35 \%$ with a mean discount amount of $25 \%$.

Table 1 contains details and results of the experiments. All but two of the experiments were significantly higher as assessed with a chi-square test. When consumers co-produced the delivery time aspect of the communication process by informing the restaurants of their preferences, purchase redemptions were higher than those who did not co-produce. Redemption rates for co-produced m-coupons ranged from $16.0 \%$ to $37.5 \%$, compared to a non-co-produced range of $5.8 \%$ to $11.6 \%$, across the 11 experiments providing ample support for $\mathrm{H} 1$.

Insert Table 1 about here

\section{Discussion}

Across all of the m-coupon campaigns in Study 1, the purchase redemption for consumers co-producing the communication process was higher compared to non-co-producers. In addition, one restaurant recorded the number of new versus current customers who opted-in. New customers accounted for $40 \%$ of the opt-in consumers, suggesting purchase redemptions may have increased incremental sales. Study 1 empirically illustrates the successful application 
of a co-production strategy to communication. The results imply marketers wishing to enter consumers' personal media should avoid standardized communications used in mass media. Enabling consumers to co-produce some aspect of the communication process creates personally relevant messages playing to the strength of personal media. Co-producing communications in this context adds value to consumers, allowing them to receive a more relevant, usable communication, which in turn leads to a stronger purchase redemption rate for firms.

\section{Study 2}

Hypotheses Development and Conceptual Model

Building off the results from Study 1, Study 2 investigates psychological responses to coproducing some aspect of the communication process for an m-coupon. The conceptual model in Figure 1 adapts endogenous constructs from studies assessing mass media marketing communication to a personal media context. In particular, attitude toward the marketing communication and purchase intent are important antecedents, which typically correlate strongly with purchase behavior (Ajzen 1991; Muehling and McCann 1993). The effect of co-producing some aspect of the communication process, which is modeled with perceived customization, and the effects of perceived risk and coupon proneness are included to hypothesize their effects on attitude and purchase intent in a personal media context.

Insert Figure 1 about Here

Consistent with Study 1, Study 2 uses a text message m-coupon and the opportunity to co-produce the delivery time to represent the co-produced aspect of the communication process. This type of digital communication does not exist until consumers specify when they prefer to 
receive it. Therefore, perceived customization represents subjects' perception that the act of coproducing this characteristic of the message creates a customized delivery time based on a preference communicated to a firm.

One interesting possibility related to personal media communication is that perceived risk may be present (Sultan, Rohm, and Gao 2009). Perceived risk is defined here as a consumer's perception of potentially adverse consequences in relation to receiving a communication from a firm (Dowling and Staelin 1994). Perceived risk has numerous conceptualizations within the marketing literature, but often represents a consumer's perception of a negative outcome in a given situation or task, such as an unwanted result, cause to worry, or uncertainty (Dowling and Staelin 1994). The present study adopts Taylor's (1974) psychological aspect of perceived risk when receiving a communication. Consumers experience an increase in risk when opening up their mobile phone to marketers due to unknown factors such as future messages exceeding optimal frequency, being overly intrusive, and lacking timeliness or relevance (Barwise and Strong 2002; Dickinger and Kleijnen 2008). Concern over any of these factors increases risk perception of a potentially negative outcome (Deighton and Kornfeld 2009). This representation of concern over a potential negative outcome is consistent with psychological discomfort when referring to perceived risk (Zaltman and Wallendorf 1983).

One mechanism to reduce risk perception is the act of giving a consumer a choice (Taylor 1974). Granting a choice is a form of co-production and customization (Etgar 2008). In turn, customization increases the perception of control (Auh et al. 2007; Bateson 1985). The perception of control reduces perceived risk when using remote technology services offered by firms (Lee and Allaway 2002). Moreover, co-production and customization are theorized as riskreducing techniques because consumers can reduce ambiguity, worry, or concern for a negative 
outcome by exerting their preferences (Etgar 2008). In the current context, co-producing the communication process creates a communication customized to some degree based on a consumer's preference. Thus, perceived customization reduces the perceived risk of personal media communication.

H2: Perceived customization has a direct, negative effect on the perceived risk of receiving a communication sent to personal media.

Attitude toward the communication is defined here as a tendency to respond favorably or unfavorably to a particular marketing communication (Lutz 1985). Attitude toward a traditional marketing communication is more favorable when the message contains useful and relevant information (Muehling and McCann 1993). The essence of co-production and customization is consumers indicating what preferences are more useful and relevant. This logic is applied in the current context by hypothesizing customization will improve attitude. In addition, perceived customization has an indirect effect on purchase intent through attitude, as research suggests attitude fully mediates this relationship (Ajzen 1991; Muehling and McCann 1993).

H3: Perceived customization has a direct, positive effect on attitude toward the communication sent to personal media.

H4: The effect of perceived customization on purchase intent is fully mediated through attitude toward the communication.

Risk perception has a significant influence on consumers to engage in new technologies and is an antecedent of attitude toward new technologies (Pavlou 2003). Swilley (2010) suggests violation of privacy and uncertainty associated with personal media are potential negative outcomes, which result in perceived risk having a negative influence on attitude toward mobile phones. Such potentially negative outcomes are what consumers are apprehensive about regarding communication sent to personal media (Hennig-Thurau et al. 2010).

H5: Perceived risk has a direct, negative effect on attitude toward the communication. 
Low risk situations are of little concern to people, but as risk goes above some baseline context value, there is more of a need to reduce it (Kahneman and Tversky 1979; Taylor 1974). As previously stated, co-production and customization are methods for risk reduction (Etgar 2008). If this is the case, then the impact of a high degree of perceived risk on attitude should be attenuated with a high degree of perceived customization. Moreover, perceived customization should produce a beneficial impact on the risk $\rightarrow$ attitude relationship, thus improving attitude. However, this risk $\rightarrow$ attitude relationship will reduce attitude when there is a lower degree of perceived customization. In summary perceived customization moderates the effect of perceived risk on attitude.

H6: A higher degree of perceived customization will attenuate the effect of perceived risk on attitude toward the communication.

The inclusion of the coupon proneness construct in the model is relevant due to the experimental stimuli being a communication in the form of an m-coupon. Coupon proneness is defined as an incremental propensity to respond to a purchase offer because the coupon form of the purchase offer positively affects purchase evaluation (Lichtenstein, Netemeyer, and Burton 1990). Prior studies examining traditional paper coupons show support for the relationship between an increase in coupon proneness and an increase in attitude toward a coupon (Lichtenstein, Netemeyer, and Burton 1990; Mittal 1994; Shimp and Kavas 1984). Similar support is put forth in a theoretical framework for non-traditional coupons available for download from Web sites (Fortin 2000). In addition, extant m-coupon research has included coupon proneness measures as the basis to form multiple groups to use for moderation assessments on an endogenous attitude construct (Dickinger and Kleijnen 2008), yet has not modeled the direct effect of coupon proneness on attitude. H7 fills this gap.

H7: Coupon proneness has a direct, positive effect on attitude toward the communication. 
An additional interaction effect between perceived customization and coupon proneness, as related to attitude toward the communication, is hypothesized. Consumers have a favorable response when coupons match preferences, such as a coupon for a preferred brand (Bawa, Srinivasan, and Srivastava 1997). Coupons possess several characteristics upon which a consumer's preference can be matched, such as preferred brand, location, redemption time, media distribution channel, face value, and the type of deal offered (Neslin and Clarke 1987). Characteristics such as these create an overall perception of attractiveness for coupons (Swaminathan and Bawa 2005). In the context of the present study, time is a key factor which creates more favorable disposition toward coupon use. With traditional paper coupons it takes time for consumers to search for, clip, save, and locate a coupon when redeeming (Babakus, Tat, and Cunningham 1988). The added time requires added effort, which forms a non-monetary cost that adversely affects one's perceived value of coupon usage (Bawa and Shoemaker 1987), and ultimately makes a coupon less attractive (Colombo, Bawa, and Srinivasan 2003).

It's possible that enabling consumers to customize creates a more attractive coupon offering by better matching a consumer's preference. In particular, customizing the delivery time of an m-coupon comparatively minimizes the time needed to search for, clip, save, and locate a traditional paper coupon for redemption. When compared to a lower degree of perceived customization, the impact of a higher degree of perceived customization should somewhat neutralize the effect that a lower degree of general coupon proneness would have on attitude. Moreover, a lower level of coupon proneness should lead to a less favorable attitude, yet a higher degree of perceived customization should increase the strength of this coupon proneness $\rightarrow$ attitude relationship. 
H8: A higher degree of perceived customization will produce a stronger positive effect of coupon proneness on attitude toward the communication compared to a lower degree of perceived customization.

\section{Method and Design}

An online survey collected data from subjects who were randomly assigned to either a co-production or non-co-production situational condition. The description of the survey given to subjects was a restaurant opening a new location near them needed feedback on potential marketing communications. The restaurant used was fictitious to reduce the occurrence of prior positive / negative attitudes or experiences with a particular firm influencing the results. Respondents completed the four coupon proneness items prior to the experimental stimuli exposure, in an effort to assess each participant's general level of coupon proneness.

All of the information between the two conditions was identical, except for the ability to co-produce or not co-produce the delivery time aspect of the communication process. Subjects were told what an m-coupon was and that consumers were required to opt-in to receive messages. In the co-production condition the subjects were shown a screenshot of a Web form used to opt-in to receive m-coupons. Subjects also were shown two form fields they could use to customize their preferred delivery day and time of the m-coupon. In the non-co-production condition these two fields were not present. All subjects then viewed an image of a mobile phone with a text message m-coupon on the screen good for $25 \%$-off-a-meal. Subjects were asked to imagine this m-coupon was sent to their phone. Subjects in the co-production condition were asked to imagine receiving the m-coupon on their desired day and time. The survey was then completed.

Sample 
Consumers responded to an ad posted on a popular U.S. social media site, indicating respondents were needed to participate in exchange for financial compensation. Investigations of factor structures, means, standard deviations, and reliabilities of data from consumers who respond to such online ads show the data do not vary from in-person paper-and-pencil data or inperson computer-based lab data (Howell et al. 2010). Furthermore, collecting respondents through social media ads is used currently by researchers (e.g. Dickinger and Kleijnen 2008).

Subjects within the convenience sample were screened based on: owning a mobile phone and being non-students. Following established practice using online samples (e.g. Landwehr, McGill, and Herrmann 2011), participants were removed if the survey was completed in less than half the expected time or had a monotonous answering pattern. This resulted in a final sample of $\mathrm{N}=332(57 \%$ female, $\mathrm{M}$ age $=34$ years old, $\mathrm{M}$ income $=\$ 55,000)$.

\section{Construct Measures}

Modified scales from prior research measured the latent constructs. All scales contain multiple items using seven-point Likert scales with extreme bi-polar anchors (i.e. strongly disagree/agree). Four items are used to measure perceived customization in order to capture respondents' perceptions of the customized delivery time of the communication. Wording and items were adapted from previous scales (Coulter and Coulter 2002; Steenkamp and Geyskens 2006) to measure perceived customization, with wording changes to reflect the delivery time aspect and mobile context. The perceived risk construct scale was adapted using four items from Cox and Cox (2001) to assess the degree of a negative outcome associated with receiving the communication. The attitude toward the communication scale was adapted using four items from Holbrook and Batra (1987). This scale assesses attitude toward ads and attitude toward coupons. The purchase intent scale was adapted using four items from MacKenzie, Lutz, and Belch (1986) 
to assess the likelihood of purchase by redeeming the m-coupon. The coupon proneness scale was adapted using four items from Lichtenstein, Netemeyer, and Burton (1990). Table 2 lists items, standardized factor loadings, t-values, and reliabilities.

\author{
Insert Table 2 about Here
}

\title{
Data Analysis Procedure
}

Structural equation modeling (SEM) assessed the psychometric properties of the constructs, model fit, and H2-H8. The inclusion of co-production and non-co-production situational conditions created experimental-like data. The authors followed the recommendations proposed by Bagozzi (1977) when using SEM to assess this type of data. This technique uses a multiple item measure (perceived customization) to represent the dichotomous groups (coproduction or non-co-production) in the data, which produces a larger variance to help assess relationships in the model while controlling for measurement error. MacKenzie (2001) states SEM's advantages make it ideal to use with experimental-like data.

\section{Results}

A marker variable assessed whether common method bias inflated or deflated the results within the cross-sectional data. A theoretically unrelated single-item measure (I like to day dream) on a seven-point Likert scale anchored by strongly disagree / strongly agree served as the marker. The two lowest correlations with this marker $(r=.002$ and $r=-.004)$ are well below the suggested .20 threshold for problematic method variance (Malhotra, Kim, and Patil 2006). Nonetheless, a discounted correlation matrix using the more conservative bias estimate $(r=-$ .004) was compared to the unadjusted matrix per Lindell and Whitney (2001). All correlations 
remained significant with signs unchanged. In sum, method bias is not a significant risk to the data.

Two manipulation checks of the co-produced versus non-co-produced subject groups assessed if the experimental manipulation was successful. First, the four manifest items assessing perceived customization were summed and averaged to compare the co-producers and the nonco-producers. The co-producing subjects had a significantly higher level of perceived customization $(\mathrm{M}=5.82, \mathrm{SD}=1.15, p<.001)$ compared to the non-co-producing subjects $(\mathrm{M}=4.04, \mathrm{SD}=1.84)$. Second, a single item to assess the attractiveness of the coupon (This coupon is attractive) measured on a seven-point Likert scale anchored by strongly agree / strongly disagree was included in regard to H8. The co-producing subjects believed the coupon was significantly more attractive $(\mathrm{M}=4.35, \mathrm{SD}=1.70, p<.05)$ than the non-co-producers $(\mathrm{M}=3.94, \mathrm{SD}=1.82)$. Taken together, the experimental manipulation was deemed to be a success.

The psychometric properties of the constructs were evaluated through confirmatory factor analysis (CFA). Each item was allowed to load on one factor and could not cross-load on other factors. In addition, all constructs were tested simultaneously in one model. The results show the measurement model fit the data well $(\chi 2=340.04, d f=160, \chi 2 / d f=2.13 ; \mathrm{CFI}=.97 ; \mathrm{TLI}=.97$; RMSEA $=.058$; RMSEA 90\% CI: .050-.067). The chi-square statistic was significant $(p<.001)$; however, chi-square is sensitive to larger samples ( $n>200$; Hu and Bentler 1999). All measures in the analysis were assessed to be reliable, with construct reliability estimates ranging from .84 to .95 . All items loaded strongly and significantly on their respective factors, ranging from .70 to .95 . Convergent validity was established with each latent variable's AVE exceeding .50 (Fornell and Larcker 1981). Discriminant validity was established with the square root of the AVE for each construct exceeding the correlation between all other constructs (Fornell and 
Larcker 1981). Table 3 contains each construct's mean, standard deviation, AVE, reliability estimate, and the results for the CFA.

Insert Table 3 about Here

Next, the structural model (see Figure 1) was tested and provided an excellent fit to the data $\left(\chi^{2}=542.51, d f=226, \chi^{2} / d f=2.40 ; \mathrm{CFI}=.95 ; \mathrm{TLI}=.95 ; \mathrm{RMSEA}=.065 ; \mathrm{RMSEA} 90 \% \mathrm{CI}\right.$ : .058-.072). Perceived customization had a strong, positive relationship with co-production; and all hypothesized standardized path coefficients were significant and in the expected direction. The results fully support the direct paths in $\mathrm{H} 2, \mathrm{H} 3, \mathrm{H} 5$, and $\mathrm{H} 7$. Perceived customization had a negative path coefficient with perceived risk and a positive path coefficient with attitude toward the communication. Perceived risk had a negative path coefficient with attitude toward the communication. Coupon proneness had a positive path coefficient with attitude toward the communication. Table 4 provides results of the structural model testing including standardized path estimates and $\mathrm{R}^{2}$ estimates.

Insert Table 4 about Here

The bootstrap procedure recommended by Zhao, Lynch, and Chen (2010) assessed the indirect effect in H4. This method was chosen over the Sobel test because it is a more powerful assessment of mediation (Preacher and Hayes 2008). A 2,000-iteration analysis shows the standardized indirect effect of perceived customization on purchase intent was positive (.42) and significant $(p<.001)$. Furthermore, the results of the confidence interval show a 95\% confidence level of the true value for the standardized indirect effect lies between .32 and .51. Baron and Kenny's (1986) four step mediation test was then used in SEM to determine partial or full mediation. The direct effect of perceived customization $\rightarrow$ attitude toward the communication, 
and attitude toward the communication $\rightarrow$ purchase intent were each significant. Then the direct effect of perceived customization $\rightarrow$ purchase intent was found to be significant in isolation. Finally, the effect of perceived customization $\rightarrow$ purchase intent was no longer significant when all constructs and paths were entered into the model simultaneously, thus illustrating full mediation. Moreover, H4 is supported as attitude toward the communication fully mediates the relationship between perceived customization and purchase intent.

The interaction effects in $\mathrm{H} 6$ and $\mathrm{H} 8$ were assessed using the method suggested by Mathieu, Tannenbaum, and Salas (1992) and endorsed by Cortina, Chen, and Dunlap (2001) for an interaction of two multi-item constructs in SEM. The reliability for each of the interaction terms was estimated using the formula put forth by Bohrnstedt and Marwell (1978). This technique creates each interaction term and adds each to the model as a separate construct. The reliabilities and squared correlations from the two independent linear terms are used to calculate the lambda and variance for each of the added interaction constructs. Results of the model with and without the included path for each of the interaction constructs were compared separately.

Table 5 presents the fit statistics and the change in $\chi^{2}$ values which assess H6 and H8. The change in $\chi^{2}$ indicates a significant interaction term for H6 $\left(\Delta \chi^{2}=8.2, \Delta d f=1, p<.01\right)$ and in the hypothesized direction. Perceived customization interacted with perceived risk $(\beta=.14 ; p<.01)$, as related to attitude. A higher degree of perceived customization in situations with a higher degree of perceived risk increases attitude significantly, compared to a lesser degree of perceived customization. Moreover, H6 is supported as perceived customization significantly attenuates the perceived risk $\rightarrow$ attitude effect, leading to a higher attitude.

The change in $\chi^{2}$ indicates a marginally significant interaction term for $\mathrm{H} 8\left(\Delta \chi^{2}=2.7, \Delta d f\right.$ $=1, p<.10)$ in the predicted direction. Perceived customization and coupon proneness have a 
marginally significant interaction effect $(\beta=.08 ; p<.10)$, as related to attitude. It's noteworthy to point out the selected method of assessing this interaction in a structural model is a strict test. A follow up regression analysis of this hypothesized interaction effect provides more acceptable support $(\beta=.09, \mathrm{t}(3,328)=2.00, p<.05)$. However, we choose to label H8 as marginally significant based on the more rigorous assessment. This interaction suggests a lesser degree of coupon proneness and a higher degree of perceived customization leads to higher attitude toward the communication, compared to a lesser degree of coupon proneness and a lesser degree of perceived customization. Moreover, enabling consumers to co-produce improves attitude toward the communication for those consumers possessing a lesser degree of coupon proneness.

Insert Table 5 about here

\section{Discussion}

The results of the hypotheses testing from Study 2 illustrate the effect of co-production when used with direct marketing communication disseminated to personal media. The conceptual model centers around perceived customization's effect on the other constructs in the model. Perceived customization functions as a risk-reducing construct, both directly and interacting with perceived risk in the risk $\rightarrow$ attitude relationship. While customization has been mentioned as a risk reducing technique in the co-production of products, Study 2 expanded this effect to risk perception regarding marketing communication.

An examination of the results reveal perceived risk is above the mid-point of the scale (M $=4.27, \mathrm{SD}=1.85)$ for non-co-producers of the communication process. In contrast, perceived risk is significantly lower for co-producers $(p<.001, \mathrm{M}=2.99, \mathrm{SD}=1.79)$. Thus, risk perception is present in personal media communication, yet reduced with co-production. 
Not all consumers are predisposed to react favorably to certain marketing communications, such as a coupon discount offer. Coupon proneness assesses this propensity. The marginally significant interaction in H8 suggests that a co-production strategy may be one mechanism to transform a less favorable initial reaction to m-coupons to a more favorable reaction which can improve one's attitudinal response. A co-produced communication strategy in this context may engender certain consumers to respond to this type of promotion, who otherwise would have a limited amount of interest. This finding is financially interesting due to the assertion that consumers who respond to coupon offers have a proclivity for higher dollar amount purchases per order and higher purchase frequencies (Hale 2010).

\section{General Discussion and Conclusions}

\section{Summary and Implications}

The overarching theoretical contribution of this paper is the conceptual shift concerning marketing communication sent to personal media as an attention-getting promotion disconnected from direct consumer participation to a service-like, participatory offering. The agent of change driving this shift is evolving technology, which requires marketers to enable consumers to participate in interactive decision making in the communication process. This conceptual shift aligns well with various service orientations, such as service logic, service-dominant logic, and unified services theory, each of which identify co-production as an element within the provision of service. Some marketers will quickly dismiss this alternative notion by arguing marketing communication and service have never been closely associated. However, improvements to a long standing system require a new or alternative paradigm (Kuhn 1996). An important 
theoretical implication is that co-production is not limited to service outcomes. Consumers can effectively co-produce marketing communication to produce mutually beneficial exchange.

Related to this overarching contribution is an additional theoretical implication which improves communication theory by expanding the understanding of push versus pull marketing communication. Acknowledging co-production as a relevant personal media communication strategy improves upon the mass media communication process. Mass media derives its model from mass communication theory, which is the process currently applied by marketers in personal media, albeit with limited success. An improvement to marketing communication theory acknowledges consumer involvement in co-producing the communication process, as this will usher in an improved practice appropriate for personal media. In this sense, co-production centers around push versus pull marketing communication and who has input into a message: firms (push) or consumers (pull). Heavier reliance on pull is one implication of a service orientation applied to promotion. Panel A in the top portion in Figure 2 shows that the current opt-in strategy for personal media enables consumers to pull communications by agreeing to be an audience. However, after this initial pull action, firms reassume a traditional push mentality. Consumers are enabled to pull for a moment, followed by firm-controlled push messages.

Insert Figure 2 about here

The current paper suggests the firm-consumer push-pull encounter must involve an additional, more participatory pull-like process given to consumers. Panel B in Figure 2 accounts for this by expanding the push-pull mindset. As depicted, the push-pull continuum widens when introducing pull with co-production. The expanded continuum grants more participation to consumers aside from the initial opt-in decision. To truly enable communication to be more effective and valuable to consumers and firms, a deeper level of participation must be offered to 
consumers. The degree of participation may vary, but it must be more than opting to become a passive target to communications. After the decision to opt-in, consumers are actively involved in pull-like decisions. Consistent with this logic, the previously labeled pull is more accurately characterized as pull with firm production, as consumers initially decide to opt-in with a pull-like action, but then the firm controls and produces standardized communication. After enabling consumers to co-produce, the stages within the communication process then play out. The right side of Figure 2 is a new concept to marketing communication. Consumers are now enabled to provide not only passive, but also active feedback with co-production. Providing active feedback in this manner gives firms the opportunity to avoid duplicating several decades of ineffective marketing communication (Rust and Oliver 1994).

This implication of co-produced communication is a major shift away from strategies and concepts within traditional marketing communication (Duncan and Moriarty 1998; Godfrey, Seiders, and Voss 2011) and personal media marketing communication (Deighton and Kornfeld 2009; Shankar et al. 2010; Sultan, Rohm, and Gao 2009). Whether a firm uses traditional or personal media, in either case attempts are made by a company to infer consumer preferences and/or exploit existing information about particular consumers. The inference and/or exploitation arises from information available to a firm through primary (i.e. individual customer records) or secondary (i.e. mining online databases and sources) information. However, the information is not specifically provided from a consumer to a firm for a particular communication exchange. The information may be accurate for a consumer, but it may not be context specific for a particular communication exchange. This lack of context is a gap that is now filled with a coproduction communication strategy. 
Co-production is a dramatic move to escape the dependence of marketers on the need to infer or exploit consumer information; and a major addition to personal media frameworks. Whereas Deighton and Kornfeld's (2009) interactivity paradigms include thought tracing and activity tracing in an attempt to gather information second-hand, a co-production strategy offers customer-specific information to a firm first-hand. In addition, the interactivity paradigms of property, social, and cultural exchanges have roots in marketers wanting to have a pedestal to persuade or manipulate consumers either apparently or covertly. Co-production creates a communication exchange based on transparency, relevance, and usefulness while providing high degrees of identity and meaning. The identity of the consumer is known along with preferences; and the meaning of the brand to each consumer becomes clearer with a higher degree of contextual meaning. Personal media enable consumers to talk back to firms with active feedback, meaning the era of the communication exchange in addition to property exchange has begun.

Co-production is a form of consumer empowerment, which is in line with the shifting balance of media power toward consumers and away from firms. Co-production of marketing communication disrupts this power balance by allowing for more assertiveness on the part of the consumer. This control of the interaction by the consumer goes beyond the five digital paradigms discussed by Deighton and Kornfield (2009) to one that is a communication exchange. An understanding of the conditions under which the communication exchange takes place can give a better understanding of when and how consumers are more willing to exert their power. Firms need to understand the barriers they need to overcome in order to invite the communication exchange. Both firms and consumers should have an understanding of the outcomes each party is willing to entertain for the communication exchange to be a success. 
The evolution toward co-produced communication brings us to an interesting question: which characteristics of personal media communication are viable alternatives to enable consumers to co-produce? Under the premise of Lancaster's (1966) characteristics theory, the value of personal media marketing communication is not the marketing message itself, but rather the function of the attributes of the communication. This rationale is consistent with attractiveness theory used in traditional promotions research (Bawa, Srinivasan, and Srivastava 1997; Swaminathan and Bawa 2005). Similar to how products contain many valuable characteristics that create utility for a consumer, these newer forms of marketing communication also contain valuable characteristics. One characteristic of marketing communication (delivery time) is shown to produce favorable outcomes for firms and consumers across both studies, yet additional characteristics are viable options for firms to enable consumers to co-produce.

Figure 3 presents a suggested personal media co-production framework divided into three stages: pre-communication, communication, and post-communication. The top portion of Figure 3 presents a number of characteristics present within personal media marketing communication ideally suited to co-produce. It is important to note that Figure 3 does not make any normative predictions of which characteristics should be applied in certain marketing contexts. Providing this type of non-normative framework supplies a broad picture of co-production possibilities and will aid in the future work of assessing co-produced personal media communication.

In the pre-communication stage marketers make available certain communication characteristics ideally suited for co-production in a given context. Among these characteristics there is delivery time (i.e. day of the week or time of day) when a consumer prefers to receive a communication, frequency of messages sent to a consumer, a consumer's preferred location, message format (such as plain text, an image, or a video embedded within a communication), 
specific type of product a consumer prefers to receive messages about (i.e. subject of a communication), enabling a consumer to choose who is a recipient of a message (i.e. a consumer recommending a brand's message to a friend), type of communication preferred (such as a discount message or an informational message), and the economic incentive ${ }^{1}$. Certain consumers and brands may find varying levels of value among the different characteristics, but this list provides a basis for a beginning to consider what consumers can co-produce in communication.

Insert Figure 3 about here

The middle portion of Figure 3 is the communication stage, which represents a consumer receiving a marketing communication that he or she co-produced. The bottom portion of Figure 3 is the post-communication stage. This stage represents post-communication outcomes for consumers and firms, several of which were assessed across both studies in the current paper. Enabling consumers to co-produce communication characteristics may lead to an increase in consumer purchase intent, an increase in consumer attitude toward the communication, an increase in consumer response rate (i.e. purchases), an increase in consumer word-of-mouth (WOM) recommendations, a decrease in consumer perception of risk, a decrease in consumer opt-out rate, and an increase in consumer satisfaction. Future research may be able to build upon this foundation to identify additional co-production options and positive outcomes for firms and consumers. One particularly interesting area of future research would be to assess the weighted importance to consumers of the various characteristics open to co-production and how these characteristics affect different outcomes.

\footnotetext{
${ }^{1}$ Internet sites such as priceline.com enable consumers to specify a price for a product. While this is a viable business model for core product offerings, the idea may also be useful for discount amounts made available to consumers via marketing communication.
} 
Another theoretical implication emerges by juxtaposing the goods-services contrast to the mass-personal media contrast. The goods-dominant logic is a derivative of mass manufacturing (Vargo and Lusch 2004), upon which a guiding philosophy for mass media communication emerged. This philosophy was that firms would operate as a sole decision maker within mass media, similar to the efficiencies achieved by excluding consumer participation in standardized, mass manufactured goods (Vargo and Akaka 2009). The position of this research is that service logic, service-dominant logic, and unified services theory are the prevailing ideologies for marketing communication sent through personal media. Moreover, the production process for goods versus services is similar to the production process for mass media versus personal media communication, respectively. A key differentiating factor is co-produced communication.

Typically in mass media marketing communication a firm investigates many of the elements contained in Figure 3. A firm infers the best options to drive a specific outcome for itself in an effort to produce the largest marginal impact on consumer purchasing or persuasion. Test marketing may occur, often referred to as A/B testing, in small groups of consumers, yet the marketer is still the chief decision maker largely basing judgments on inference without direct consumer participation in the decision making process. Passive consumers provide general information upon which marketers make decisions. The introduction of co-production into communication enables a marketer to forgo $\mathrm{A} / \mathrm{B}$ testing by enabling consumers to actively choose A or B. This is a world of change that marketing, in a communication context, has not experienced before. Figure 2's two types of feedback align with this change. Traditionally in mass media firms push out messages and then assess the results with passive feedback. Now in personal media firms can involve consumers by granting co-production opportunities. This is active feedback, in that, consumers are no longer a passive audience, but now become active 
participants in the communication process. The emergence of co-production and active feedback introduces a potentially rich area for behavioral and modeling researchers, such as including coproduction in the comparison of $\mathrm{A} / \mathrm{B}$ testing ( $\mathrm{A}$ or $\mathrm{B}$ or co-production). Future research can examine if the benefits of co-producing some of Figure 3's elements will trade off against a firm's persuasion or behavioral goals.

Interestingly, mass media marketing communication may also benefit from a coproduction strategy. Years ago this was impossible, but now the evolution of technology and media makes this a reality. The anticipated growth of interactive television requires new thinking into how mass promotional communication through this medium will include consumer participation. In addition, mobile television and multiscreen marketing are estimated to have exponential growth in the near future, which will morph a mass medium with personal media (television, social media, and mobile devices). Marketers must avoid old ways of thinking by limiting consumer participation with newer media to opting-in to become a passive audience.

Three noteworthy managerial implications demand attention. First, although not formally hypothesized, as a point of comparison in Study 1 the purchase redemption of a paper coupon with the exact same verbiage and face value was compared to the m-coupon campaign for one restaurant. Paper coupons were manually distributed to people in the surrounding geographic area. Consumers who wanted the coupon were given a form requiring them to check a box and answer two brief questions (to account for minimal effort required by consumers who opt-in to receive an m-coupon). Purchase redemption was 3\% for the paper coupon campaign, which is typical for paper coupons in the U.S. (historically $1 \%$-to-3\%). These results suggest an opportunity for marketers to widen the purchase redemption gap between paper and m-coupons. 
Second, a co-production strategy in this context provides guidance to firms that are struggling to use sales promotions with personal media. An example is the economic losses by firms using social couponing through Groupon and similar services (Kumar and Rajan 2012). Firms recognize promotions are needed through new media to spur customer activity; however social coupons appear to be a losing proposition due to the massive discounts $(50 \%+)$ and fees. In contrast, the current paper's Study 1 illustrates how co-production is successfully used with a personal media sales promotion at a more acceptable discount rate.

Third, co-production may lead to an increase in consumer opt-in rates. Opt-in must occur before exposure to messages, and identifying ways to increase opt-in rates is important. If firms publicize consumers have more decisional input into the creation of marketing communication, this may cause some consumers to opt-in who otherwise would not participate. Risk perception is likely to be present prior to opting-in. Communicating a co-production strategy with opt-in signage and verbiage may attenuate these risks.

\section{Limitations and Future Research}

One limitation is delivery time was the only co-produced attribute of the communication process examined in both studies. It's possible to co-produce other characteristics as depicted in Figure 3's framework. Attractiveness of a promotional communication varies on a number of different characteristics of a communication, suggesting that future research can examine additional characteristics and perhaps compare the weighted importance. In particular, it would be interesting to compare co-produced discount offers with different face value amounts.

Study 1's restaurants had a high response rate, in part, due to subjects' co-producing a characteristic aligning well with the product offering. Despite the results, some firms or products 
would not benefit from customizing the timing of a communication. For example, consumers may know when they prefer to eat at a restaurant more so than when they prefer to visit a hardware store. However, the results from Study 1 point to the idea of what such a strategy offers to firms if co-producing marketing communication aligns well with a product offering.

Only a single consumer-firm co-production opportunity takes place in each study, where consumers co-produce only before receiving a single communication. Research should examine a lengthier dialogical orientation (Ballantyne and Varey 2006) where multiple communication exchanges with co-production occur. Godfrey, Seiders, and Voss (2011) suggest that consumers react negatively when the amount of communication is not at an ideal level. Future research should examine possible outcomes of co-production with varying levels of message volume and co-production opportunities. What is the ideal level of the number of co-production opportunities, and is there a balance between co-production opportunities, and specific opportunities that cannot be co-produced by the consumer?

The present investigation did not seek to identify if the increase in attitude was not only due to customization, but also consumer empowerment or the need for uniqueness. Not much is known about the psychological antecedents and outcomes of perceived customization. It is most likely a multilevel variable and this suggested area of future research would be beneficial.

Both Study 1 and 2 are limited to a convenience sample in a single product category, meaning findings may not generalize to all consumers across various products. Examination of multiple product categories, such as high versus low involvement and hedonic versus utilitarian can also be addressed by future research. Also, demographic information was not captured from consumers in Study 1. Future research should investigate how actual purchase behavior varies across demographics when using co-produced communication and personal media. 
Mobile technologies are changing the retail landscape. The interactivity between consumers, as well as consumers and retailers, may alter strategies that retailers have always considered. As Shankar et al. (2010) discuss how retailers need to anticipate the changes brought on by mobile technologies, retailers need to also understand consumer perceptions of the use of different handheld devices. The only form of personal media under investigation is mobile phone text messaging. Co-producing social media direct marketing communication, as well as the use of other personal devices, such as tablet computers, are ripe areas for future research.

Lastly, mobile marketing acceptance has been studied cross-culturally, with acceptance in both mature and emerging markets (Sultan, Rohm, and Gao 2009). However, co-production models may not be as impactful in other markets, as some cultures are irritated by mobile communications (Liu et al. 2012). An examination of cultural effects of co-production may lead to a better understanding of the new customer and retailer dynamics.

\section{References}

Ajzen, Icek (1991), "The Theory of Planned Behavior," Organizational Behavior and Human Decision Processes, 50, 2, 179-211.

Auh, Seigyoung, Simon J. Bell, Colin S. McLeod, and Eric Shih (2007), "Co-production and Customer Loyalty in Financial Services," Journal of Retailing, 83, 3, 359-370.

Babakus, Emin, Peter Tat, and William Cunningham (1988), "Coupon Redemption: A Motivational Perspective," Journal of Consumer Marketing, 5, 2, 37-43.

Bacile, Todd J. and Ronald E. Goldsmith (2011), “A Services Perspective for Text Message Coupon Customization," Journal of Research in Interactive Marketing, 5, 4, 244-257.

Bagozzi, Richard P. (1977), "Structural Equation Models in Experimental Research," Journal of Marketing Research, 14, 2, 209-226.

Ballantyne, David and Richard J. Varey (2006), "Introducing a Dialogical Orientation to the Service-Dominant Logic of Marketing" in The Service-Dominant Logic of Marketing: Dialog, Debate, and Directions, Robert F. Lusch and Stephen L. Vargo, eds. New York: M. E. Sharpe, 224-235. 
Baron, Reuben M. and David A. Kenny (1986), "The Moderator-Mediator Variable Distinction in Social Psychological Research: Conceptual, Strategic, and Statistical Considerations," Journal of Personality and Social Psychology, 51, 6, 1173-1182.

Barwise, Patrick and Colin Strong (2002), "Permission-Based Mobile Advertising," Journal of Interactive Marketing, 16 (1), 14-24.

Bateson, J. E. G. (1985), "Self-Service Consumer: An Exploratory Study, “ Journal of Retailing, 61, 3, 49-76.

Bawa, Kapil and Robert W. Shoemaker (1987), "The Effects of a Direct Mail Coupon on Brand Choice Behavior," Journal of Marketing Research, 24, 4, 370-376.

---, Srini S. Srinivasan and Rajendra K. Srivastava (1997), "Coupon Attractiveness and Coupon Proneness: A Framework for Modeling Coupon Redemption," Journal of Marketing Research, 34, 4, 517-525.

Bendapudi, Neeli and Robert P. Leone (2003), "Psychological Implications of Customer Participation in Co-Production," Journal of Marketing, 67, 1, 14-28.

Bohrnstedt, George W. and Gerald Marwell (1978), "The Reliability of Products of Two Random Variables,” in Sociological Methodology, K. F. Schuessler, ed. San Francisco, CA: Jossey-Bass, 254-273.

Brehm, Jack W. (1972), Responses to Loss of Freedom: A Theory of Psychological Reactance. Morristown, NJ: General Learning Press.

Clarke, Irvine (2001), "Emerging Value Propositions for M-Commerce," Journal of Business Strategies, 18, 2, 133-148.

Colombo, Richard, Kapil Bawa, and Srini S. Srinivasan (2003), "Examining the Dimensionality of Coupon Proneness: A Random Coefficients Approach," Journal of Retailing and Consumer Services, 10, 1, 27-33.

Cortina, Jose, Gilad Chen, and William P. Dunlap (2001), "Testing Interaction Effects in LISREL: Examination and Illustration of Available Procedures," Organizational Research Methods, 4, 4, 324-360.

Coulter, Keith S. and Robin A. Coulter (2002), "Determinants of Trust in a Service Provider: The Moderating Role of Length of Relationship," Journal of Services Marketing, 16, 1, $35-50$.

Cox, Dena and Anthony Cox (2001), “Communicating the Consequences of Early Detection: The Role of Evidence and Framing.” Journal of Marketing, 65, 3, 91-103.

Deighton, John and Leora Kornfeld (2009), “Interactivity's Unanticipated Consequences from Marketers and Marketing," Journal of Interactive Marketing, 23, 1, 4-10.

Dickinger, Astrid and Mirella Kleijnen (2008), "Coupons Going Wireless: Determinants of Consumer Intentions to Redeem Mobile Coupons," Journal of Interactive Marketing, 22, 3, 23-39. 
Dowling, Grahame R. and Richard Staelin (1994), "A Model of Perceived Risk and Intended Risk-Handling Activity," Journal of Consumer Research, 21, 1, 119-134.

Duncan, Tom, and Sandra E. Moriarty (1998), "A Communication-Based Marketing Model for Managing Relationships," Journal of Marketing, 62 (2), 1-13.

--- and --- (2006), “How Integrated Marketing Communication's “Touchpoints” Can Operationalize the Service-Dominant Logic" in The Service-Dominant Logic of Marketing: Dialog, Debate, and Directions, Robert F. Lusch and Stephen L. Vargo, eds. New York: M. E. Sharpe, 236-244.

eMarketer (2010), “Mobile Users Ready for Location-Based Text Marketing," (accessed January 20, 2011), [available at http://www.emarketer.com/Article.aspx?R=1007782].

Etgar, Michael (2008), “A Descriptive Model of the Consumer Co-Production Process,” Journal of the Academy of Marketing Science, 36, 1, 97-108.

Firat, A. Fuat and Nikhilesh Dholakia (2006), "Theoretical and Philosophical Implications of Postmodern Debates: Some Challenges to Modern Marketing," Marketing Theory, 6, 2, 123-162.

Fornell, Claes and David F. Larcker (1981), "Evaluating Structural Equation Models with Unobservable Variables and Measurement Error," Journal of Marketing Research, 18, 1, $39-50$.

Fortin, David R. (2000), "Clipping Coupons in Cyberspace: A Proposed Model of Behavior for Deal-Prone Consumers," Psychology \& Marketing, 17, 6, 515-534.

Godek, John, J. Frank Yates, and Yeosun Yoon (2002), “Customization and Personalization: The Influence of Perceived Control and Perceived Capability on Product Evaluations," Advances in Consumer Research, 29, 1, 157.

Godfrey, Andrea, Kathleen Seiders, and Glenn B. Voss (2011), "Enough Is Enough! The Fine Line in Executing Multichannel Relational Communication," Journal of Marketing, 75 (4), 94-109

Graham, Phil (2007), "Political Economy of Communication: A Critique," Critical Perspectives on International Business, 3, 3, 226-245.

Grönroos, Christian (2006), "Adopting a Service Logic for Marketing," Marketing Theory, 6, 3, 317-333.

Hale, Todd (2010), “The Coupon Comeback," (accessed June 10, 2012), [available at http://blog.nielsen.com/nielsenwire/consumer/the-coupon-comeback/].

Hennig-Thurau, Thorsten, Edward C. Malthouse, Christian Friege, Sonja Gensler, Lara Lobschat, Arvind Rangaswamy, and Bernd Skiera (2010), "The Impact of New Media on Consumer Relationships," Journal of Service Research, 13, 3, 311-330.

Holbrook, Morris and Rajeev Batra (1987), "Assessing the Role of Emotions as Mediators of Consumer Responses to Advertising," Journal of Consumer Research, 14, 3, 404-420.

Howell, Ryan T., Katrina S. Rodzon, Mark Kurai, and Amy H. Sanchez (2010), "A Validation of Well-Being and Happiness Surveys for Administration via the Internet," Behavior Research Methods, 42, 3, 775-784. 
$\mathrm{Hu}$, Li-tze and Peter M. Bentler (1999), "Cutoff Criteria for Fit Indexes in Covariance Structure Analysis: Conventional Criteria Versus New Alternatives," Structural Equation Modeling, 6, 1, 1-55.

Huffman, Cynthia and Barbara E. Kahn (1998), "Variety for Sale: Mass Customization or Mass Confusion?," Journal of Retailing, 74, 4, 491-513.

Innis, Harold A. (1942), "The Newspaper in Economic Development," Journal of Economic History, 2, 1-33.

Kahneman, Daniel and Amos Tversky (1979), "Prospect Theory: An Analysis of Decision under Risk," Econometrica, 47, 2, 263-292.

Kuhn, Thomas S. (1996), The Structure of Scientific Revolutions (Third Edition). Chicago, IL: University of Chicago Press.

Kumar, V. and Bharath Rajan (2012), "Social Coupons as a Marketing Strategy: A Multifaceted Perspective," Journal of the Academy of Marketing Science, 40, 1, 120-138.

Lancaster, Kelvin J. (1966), "A New Approach to Consumer Theory," Journal of Political Economy, 74, 2, 132-157.

Landwehr, Jan R., Ann L. McGill, and Andreas Herrmann (2011), "It's Got the Look: The Effect of Friendly and Aggressive 'Facial' Expressions on Product Liking and Sales," Journal of Marketing, 75, 3, 132-146.

Lee, Jungki and Arthur Allaway (2002), "Effects of Personal Control on Adoption of SelfService Technology Innovations,” Journal of Services Marketing, 16, 6, 553-572.

Lichtenstein, Donald R., Richard G. Netemeyer, and Scot Burton (1990), "Distinguishing Coupon Proneness from Value Consciousness - An Acquisition-Transaction UtilityTheory Perspective," Journal of Marketing, 54, 3, 54-67.

Lindell, Michael K. and David J. Whitney (2001), "Accounting for Common Method Variance in Cross-Sectional Research Designs," Journal of Applied Psychology, 86, 1, 114-121.

Liu, Chia-Ling 'Eunice', Rudolf R. Sinkovics, Noemi Pezderka, and Parissa Haghirian (2012), "Determinants of Consumer Perceptions toward Mobile Advertising - a Comparison between Japan and Austria," Journal of Interactive Marketing, 26 (1), 21-32.

Lüders, Marika (2008), "Conceptualizing Personal Media," New Media and Society, 10, 5, 683702.

Lutz, Richard J. (1985), "Affective and Cognitive Antecedents of Attitude Toward the Ad: A Conceptual Framework" in Psychological Processes and Advertising Effects: Theory, Research and Application, L. F. Alwitt and A. A. Mitchell, eds. Hillsdale, NJ: Lawrence Erlbaum Associates, 45-63.

MacKenzie, Scott B., Richard J. Lutz, and George E. Belch (1986), "The Role of Attitude Toward the Ad as a Mediator of Advertising Effectiveness: A Test of Competing Explanations," Journal of Marketing Research, 23, 2, 130-143.

--- (2001) , "Opportunities for Improving Consumer Research through Latent Variable Structural Equation Modeling," Journal of Consumer Research, 28, 1, 159-166. 
Malhotra, Naresh K., Sung S. Kim, and Ashutosh Patil (2006), "Common Method Variance in IS Research: A Comparison of Alternative Approaches and a Reanalysis of Past Research," Management Science, 52, 12, 1865-1883.

Mathieu, John E., Scott I. Tannenbaum, and Eduardo Salas (1992), "Influences of Individual and Situational Characteristics on Measures of Training Effectiveness," Academy of Management Journal, 35, 4, 828-847.

Mittal, Banwari (1994), "An Integrated Framework for Relating Diverse Consumer Characteristics to Supermarket Coupon Redemption," Journal of Marketing Research, 31, 4, 533-544.

Muehling, Darrel D. and Michelle McCann (1993), "Attitude Toward the Ad: A Review," Journal of Current Issues and Research in Advertising, 15, 2, 25-58.

Neslin, Scott A. and Darral G. Clarke (1987), "Relating the Brand Use Profile of Coupon Redeemers to Brand and Coupon Characteristics," Journal of Advertising Research, 27, 1, 23-32.

Pavlou, Paul A. (2003), “Consumer Acceptance of Electronic Commerce: Integrating Trust and Risk with the Technology Acceptance Model," International Journal of Electronic Commerce, 7, 3, 69-103.

Payne, Adrian, Kaj Storbacka, and Pennie Frow (2008), "Managing the Co-creation of Value," Journal of the Academy of Marketing Science, 36, 1, 83-96.

Prahalad, C. K. and Venkat Ramaswamy (2004), The Future of Competition: Co-creating Unique Value with Customers. Boston, Mass: Harvard Business School Press.

Preacher, Kristopher J. and Andrew F. Hayes (2008), "Asymptotic and Resampling Strategies for Assessing and Comparing Indirect Effects in Multiple Mediator Models," Behavior Research Methods, 40, 3, 879-891.

Rust, Roland T., and Richard W. Oliver (1994), “The Death of Advertising," Journal of Advertising, 23, 4, 71-77.

Sampson, Scott E. and Craig M. Froehle (2006), "Foundations and Implications of a Proposed Unified Services Theory," Production and Operations Management, 15, 2, 329-343.

Shankar, Venkatesh and Sridhar Balasubramanian (2009), "Mobile Marketing: A Synthesis and Prognosis," Journal of Interactive Marketing, 23, 2, 118-129.

---, Alladi Venkatesh, Charles F. Hofacker, and Prasad Naik (2010), "Mobile Marketing in the Retailing Environment: Current Insights and Future Research Avenues," Journal of Interactive Marketing, 24 (2), 111-120.

Shannon, Claude E. and Warren Weaver (1949), The Mathematical Theory of Communication, Urbana, IL: University of Illinois Press.

Sheth, Jagdish N. and Rajendra S. Sisodia (2006), Does Marketing Need Reform? Fresh Perspectives on the Future. Armonk, NY: M.E. Sharp.

Shimp, Terence A. and Alican Kavas (1984), "The Theory of Reasoned Action Applied to Coupon Usage," Journal of Consumer Research, 11, 3, 795-809. 
Steenkamp, Jan-Benedict E.M. and Inge Geyskens (2006), "How Country Characteristics Affect the Perceived Value of Web Sites," Journal of Marketing, 70, 3, 136-150.

Sultan, Fareena, Andrew J. Rohm, and Tao Gao (2009), "Factors Influencing Consumer Acceptance of Mobile Marketing: A Two-Country Study of Youth Markets," Journal of Interactive Marketing, 23, 4, 308-320.

Swaminathan, Srinivasan and Kapil Bawa (2005), "Category-specific Coupon Proneness: The Impact of Individual Characteristics and Category-specific Variables," Journal of Retailing, 81, 3, 205-214.

Swilley, Esther (2010), “Technology Rejection: The Case of the Wallet Phone," Journal of Consumer Marketing, 27, 4, 304-312.

Taylor, James W. (1974), "The Role of Risk in Consumer Behavior," Journal of Marketing, 38, 2, 54-60.

VanBoskirk, Shar (2011), "US Interactive Marketing Forecast, 2011-2016," (accessed February 21, 2012), [available at http://www.forrester.com/rb/Research/ us_interactive_marketing_forecast\%2C_2011_to_2016/q/id/59379/t/2].

Vargo, Stephen L. and Robert F. Lusch (2004), "Evolving to a New Dominant Logic for Marketing," Journal of Marketing, 68, 1, 1-17.

--- and --- (2008), "Service-Dominant Logic: Continuing the Evolution," Journal of the Academy of Marketing Science, 36, 1, 1-10.

--- and Melissa Archpru Akaka (2009), "Service-Dominant Logic as a Foundation for Service Science: Clarifications," Service Science, 1, 1, 32-41.

Wind, Jerry and Arvind Rangaswamy (2001), "Customerization: The Next Revolution in Mass Customization," Journal of Interactive Marketing, 15, 1, 13-32.

Wortman, Camille B. and Jack W. Brehm (1975), "Responses to Uncontrollable Outcomes: An Integration of Reactance Theory and the Learned Helplessness Model" in Advances in Experimental Social Psychology (Vol. 8), L. Berkowitz ed. New York: Academic Press, 277-336.

Zaltman, Gerald and Melanie Wallendorf (1983), Consumer Behavior, New York: Wiley.

Zhao, Xinshu, John G. Lynch Jr., and Qimei Chen (2010), "Reconsidering Baron and Kenny: Myths and Truths about Mediation Analysis," Journal of Consumer Research, 37, 2, 197 206. 
Table 1

Results from Field Experiments in Study 1

\begin{tabular}{|c|c|c|c|c|c|c|c|c|}
\hline City & Restaurant & $\begin{array}{l}\text { \#Co-Produced } \\
\text { M-Coupons } \\
\text { Sent }\end{array}$ & $\begin{array}{c}\text { \#Co-Produced } \\
\text { M-Coupons } \\
\text { Redeemed }\end{array}$ & $\begin{array}{l}\text { Co-Produced } \\
\text { Redemption } \\
\text { Rate }\end{array}$ & \begin{tabular}{|c} 
\#Non-Co-Produced \\
M-Coupons \\
Sent
\end{tabular} & $\begin{array}{l}\text { \#Non-Co-Produced } \\
\text { M-Coupons } \\
\text { Redeemed }\end{array}$ & $\begin{array}{l}\text { Non-Co-Produced } \\
\text { Redemption } \\
\text { Rate }\end{array}$ & $\begin{array}{c}\text { Discount } \\
\text { Offer }\end{array}$ \\
\hline $\mathrm{A}$ & 1 & 68 & 17 & $25.0 \%{ }^{\mathrm{a}}$ & 57 & 6 & $10.5 \%$ & $25 \%$ \\
\hline A & 2 & 112 & 42 & $37.5 \%{ }^{\mathrm{b}}$ & 132 & 11 & $8.3 \%$ & $35 \%$ \\
\hline $\mathrm{A}$ & 2 & 121 & 37 & $30.6 \%{ }^{\mathrm{a}}$ & 140 & 13 & $9.3 \%$ & $20 \%$ \\
\hline $\mathrm{A}$ & 2 & 140 & 31 & $22.1 \%^{\mathrm{b}}$ & 151 & 17 & $11.3 \%$ & Free drink ${ }^{\mathrm{d}}$ \\
\hline A & 2 & 145 & 38 & $26.2 \%^{\mathrm{b}}$ & 153 & 14 & $9.2 \%$ & BOGO $50 \%^{\mathrm{e}}$ \\
\hline A & 3 & 81 & 22 & $27.2 \%{ }^{b}$ & 86 & 5 & $5.8 \%$ & $20 \%$ \\
\hline A & 3 & 112 & 24 & $21.4 \%^{\mathrm{b}}$ & 106 & 8 & $7.5 \%$ & Free drink ${ }^{d}$ \\
\hline $\mathrm{A}$ & 3 & 125 & 23 & $18.4 \%^{\mathrm{a}}$ & 118 & 11 & $9.3 \%$ & $20 \%$ \\
\hline $\mathrm{A}$ & 3 & 125 & 20 & $16.0 \%$ & 128 & 12 & $9.4 \%$ & BOGO $50 \%^{\mathrm{e}}$ \\
\hline $\mathrm{B}$ & 4 & 120 & 22 & $18.3 \%$ & 121 & 14 & $11.6 \%$ & $20 \%$ \\
\hline $\mathrm{B}$ & 4 & 126 & 28 & $22.2 \%^{\mathrm{b}}$ & 120 & 9 & $7.5 \%$ & Free drink ${ }^{\mathrm{d}}$ \\
\hline \multicolumn{2}{|c|}{ TOTALS: } & 1,275 & 304 & $23.8 \%^{c}$ & 1,312 & 120 & $9.1 \%$ & $25 \%$ off $^{f}$ \\
\hline
\end{tabular}

Co-produced m-coupon redemption rate is significantly higher than non-co-produced m-coupon: ${ }^{\mathrm{a}} p<.05 \quad{ }^{\mathrm{b}} p<.01 \quad{ }^{\mathrm{c}} p<.001$

${ }^{d}$ free drink with purchase of a meal is approximately an overall discount of $20 \%$ off

${ }^{\mathrm{e}}$ BOGO 50\%: buy one meal, get one meal $50 \%$ off is approximately an overall discount of $25 \%$ off

$\mathrm{f}$ the overall average discount offered across all campaigns was approximately $25 \%$ off 
Table 2

\section{Scales and Items Used in Study 2}

\begin{tabular}{|c|c|c|c|c|}
\hline Construct & Items & $\begin{array}{l}\text { Landardized Factor } \\
\text { Loading }\end{array}$ & t-values & $\begin{array}{l}\text { Construct } \\
\text { Reliability }\end{array}$ \\
\hline $\begin{array}{l}\text { Perceived customization } \\
\text { (anchored with } \\
\text { strongly disagree/strongly agree) }\end{array}$ & $\begin{array}{l}\text { - The coupon's delivery time features are customized. } \\
\text { - The delivery time features of this coupon are adaptable to my needs. } \\
\text { - Some features of this coupon can be changed by me. } \\
\text { - The day and time when the coupon is sent is customizable to meet my schedule. }\end{array}$ & $\begin{array}{l}.88 \\
.89 \\
.86 \\
91\end{array}$ & $\begin{array}{l}24.02 \\
24.84 \\
22.93 \\
*\end{array}$ & .94 \\
\hline $\begin{array}{l}\text { Perceived risk } \\
\text { (anchored with } \\
\text { strongly disagree/strongly agree) }\end{array}$ & $\begin{array}{l}\text { - Getting this coupon is risky. } \\
\text { - This coupon can lead to bad results. } \\
\text { - This coupon can lead to uncertain outcomes. } \\
\text { - Getting this coupon would cause me to worry. }\end{array}$ & $\begin{array}{l}.90 \\
.95 \\
.92 \\
.82\end{array}$ & $\begin{array}{l}29.00 \\
* \\
31.66 \\
22.91\end{array}$ & .94 \\
\hline $\begin{array}{l}\text { Attitude toward the } \\
\text { communication }\end{array}$ & $\begin{array}{l}\text { - I definitely dislike / I definitely like the coupon. } \\
\text { - I definitely react unfavorably / I definitely react favorably to the coupon. } \\
\text { - I definitely feel negative / I definitely feel positive toward the coupon. } \\
\text { - The coupon is definitely bad / The coupon is definitely good. }\end{array}$ & $\begin{array}{l}.90 \\
.94 \\
.92 \\
.88\end{array}$ & $\begin{array}{l}28.39 \\
* \\
31.22 \\
26.92\end{array}$ & .95 \\
\hline Purchase intent & $\begin{array}{l}\text { Indicate the probability that you will try this coupon for the restaurant when it } \\
\text { becomes available in your area: } \\
\text { - Definitely Unlikely / Definitely likely } \\
\text { - Definitely Improbable / Definitely probable } \\
\text { - Definitely Impossible / Definitely possible } \\
\text { - No, definitelynot / Yes, definitely. }\end{array}$ & $\begin{array}{l}.93 \\
.93 \\
.86 \\
.92\end{array}$ & $\begin{array}{l}30.45 \\
* \\
24.34 \\
29.49\end{array}$ & .95 \\
\hline $\begin{array}{l}\text { Coupon proneness } \\
\text { (anchored with } \\
\text { strongly disagree/strongly agree) }\end{array}$ & $\begin{array}{l}\text { - I am more likely to buy brands for which I have a coupon. } \\
\text { - When I use coupons, I feel that I am getting a good deal. } \\
\text { - I enjoy using coupons, regardless of the amount of money I save by doing so. }\end{array}$ & $\begin{array}{l}.71 \\
.83 \\
.78 \\
.70\end{array}$ & $\begin{array}{l}12.26 \\
* \\
12.77 \\
11.39\end{array}$ & .84 \\
\hline
\end{tabular}

NOTE: $\mathrm{N}=332$

* Denotes a path constrained to 1 for model identification 
Table 3

Means, Standard Deviations, Correlations, and Reliability Estimates for Study 2

\begin{tabular}{|c|c|c|c|c|c|c|c|c|c|c|}
\hline Constructs & Range & Mean & $\mathrm{SD}$ & AVE & $\mathrm{CR}$ & 1 & 2 & 3 & 4 & 5 \\
\hline 1. Perceived customization & $1-7$ & 4.90 & 1.78 & .78 & .94 & .88 & & & & \\
\hline 2. Perceived risk & $1-7$ & 3.66 & 1.93 & .81 & .94 & $-.37 *$ & .90 & & & \\
\hline 3. Attitude toward comm. & $1-7$ & 5.10 & 1.76 & .83 & .95 & $.53 *$ & $-.42 *$ & .91 & & \\
\hline 4. Purchase intent & $1-7$ & 5.34 & 1.63 & .83 & .95 & $.49 *$ & $-.26^{*}$ & $.79 *$ & .91 & \\
\hline 5. Coupon proneness & $1-7$ & 5.28 & 1.34 & .58 & .84 & $.27 *$ & -.03 & $.31 *$ & $.41^{*}$ & .75 \\
\hline
\end{tabular}

CFA results: $\chi 2=340.04, d f=160, \chi 2 / d f=2.13 ; \mathrm{CFI}=.97 ; \mathrm{TLI}=.97 ; \mathrm{RMSEA}=.058 ; \mathrm{RMSEA} 90 \%$ CI: $.050-.067$

$\mathrm{N}=332$; all constructs measured on seven-point scales; $\mathrm{SD}=$ Standard Deviation; AVE = Average Variance Extracted; $\mathrm{CR}=$ Construct Reliability.

The square roots of the average variance extracted for each construct are presented in bold on the diagonal of the correlation matrix.

$* p<.01$ 
Table 4

Structural Model Standardized Paths and Variance Explained Results for Study 2

\begin{tabular}{|c|c|c|}
\hline Hypothesized and Non-Hypothesized Paths & $\begin{array}{c}\text { Standardized } \\
\text { Path Coefficients }\end{array}$ & $R^{2}$ (construct) \\
\hline ---- Categorical co-production conditions $\rightarrow$ Perceived customization & $.50 *$ & .25 (Perceived customization) \\
\hline H2: Perceived customization $\rightarrow$ Perceived risk & $-.38 *$ & .14 (Perceived risk) \\
\hline H3: Perceived customization $\rightarrow$ Attitude communication & $.39 *$ & .35 (Attitude) \\
\hline H4: Perceived customization fully mediated through Attitude $\rightarrow$ Purchase intent & $.42 *$ & .62 (Purchase intent) \\
\hline H5: Perceived risk $\rightarrow$ Attitude communication & $-.27 *$ & \\
\hline H6: Perceived customization X Perceived risk $\rightarrow$ Attitude communication & $.14^{* *}$ & \\
\hline H7: Coupon proneness $\rightarrow$ Attitude communication & $.22 *$ & \\
\hline H8: Perceived customization X Coupon proneness $\rightarrow$ Attitude communication & $.08 * * *$ & \\
\hline
\end{tabular}

Structural Model Fit: $\chi^{2}=542.51, d f=226, \chi^{2} / d f=2.40 ;$ CFI $=.95 ;$ TLI $=.95 ;$ RMSEA $=.065 ;$ RMSEA 90\% CI: $.058-.072$

$$
\begin{aligned}
& * p<.001 \\
& * * p<.01 \\
& * * * p<.10
\end{aligned}
$$


Table 5

Structural Model Fit and Interaction Assessments

\begin{tabular}{c|c|c|c|} 
Fit $/$ Path & $\begin{array}{c}\text { Research model without } \\
\text { interaction constructs }\end{array}$ & $\begin{array}{c}\text { Model with Perceived } \\
\text { customization X Perceived } \\
\text { risk interaction construct }\end{array}$ & $\begin{array}{c}\text { Model with Perceived } \\
\text { customization X coupon } \\
\text { proneness interaction construct }\end{array}$ \\
$\chi^{2}|\mathrm{df}| \chi^{2} / \mathrm{df}$ & $542.51|226| 2.40$ & $534.30|225| 2.38$ & $539.86|225| 2.40$ \\
$\mathrm{CFI}$ & .95 & .95 & .95 \\
TLI & .95 & .95 & .95 \\
RMSEA & .065 & .064 & .065 \\
RMSEA 90\% CI & .058 to .072 & .057 to .072 & .058 to .072 \\
\hline
\end{tabular}




\section{Figure 1}

\section{Conceptual Model}

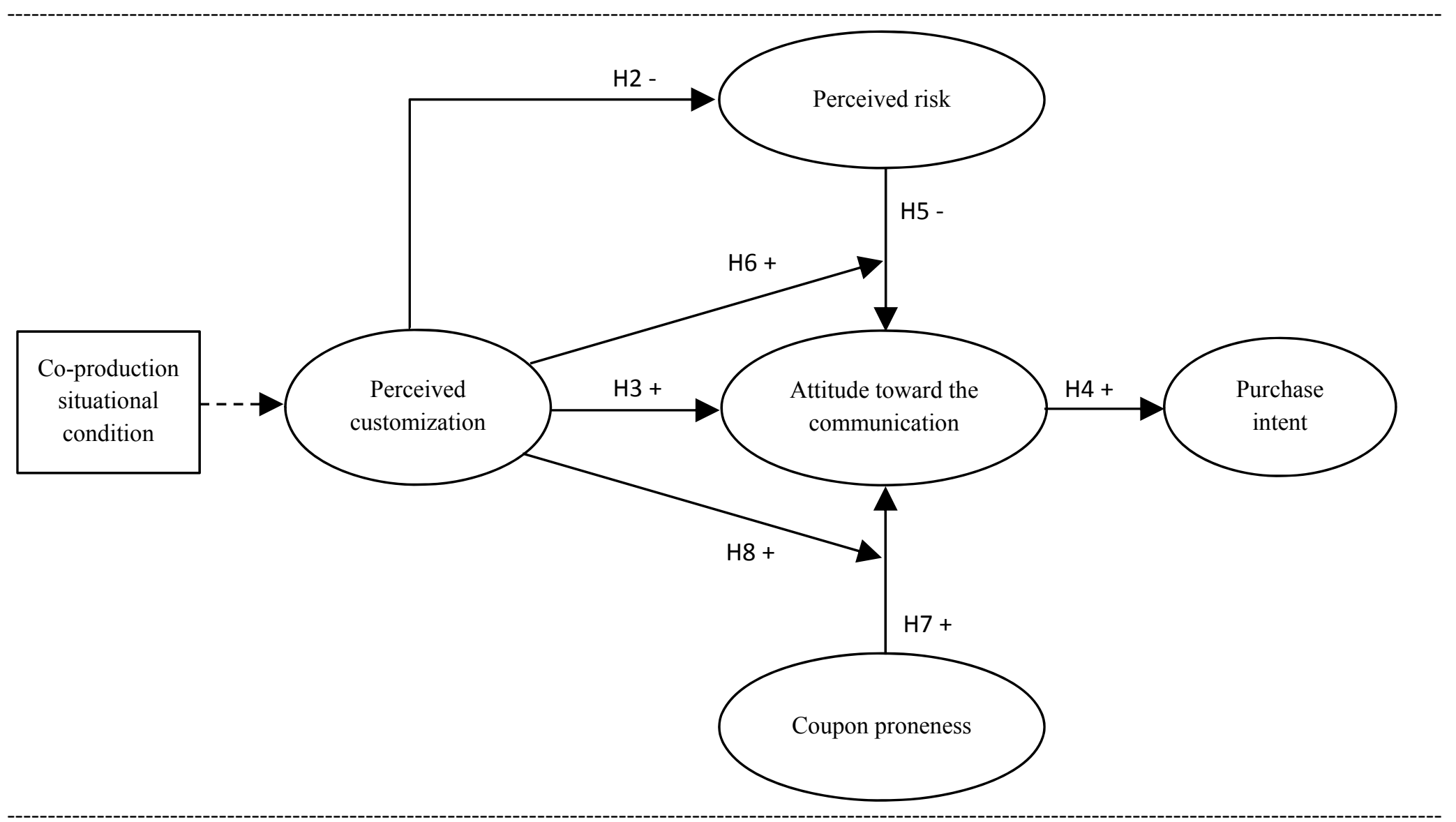

Note: - Dashed path in Study 2's structural model is supported by previous research. No formal hypothesis is tested for this path. - H4: the effect of perceived customization on purchase intent is fully mediated through attitude toward the communication. 
Figure 2

Conceptual Push-Pull Framework Featuring Co-Produced Marketing Communication

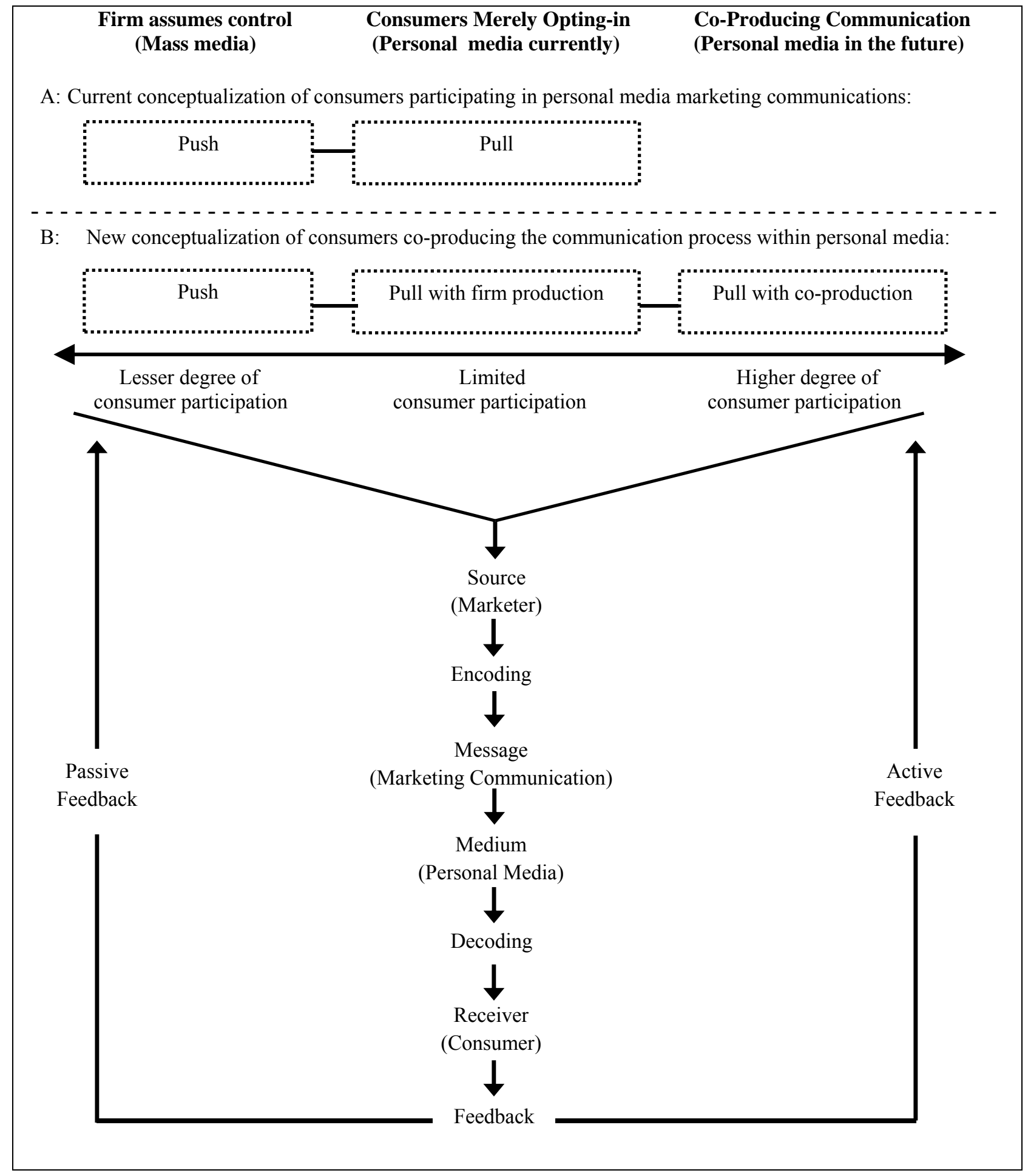




\section{Figure 3}

\section{Personal media co-production framework}

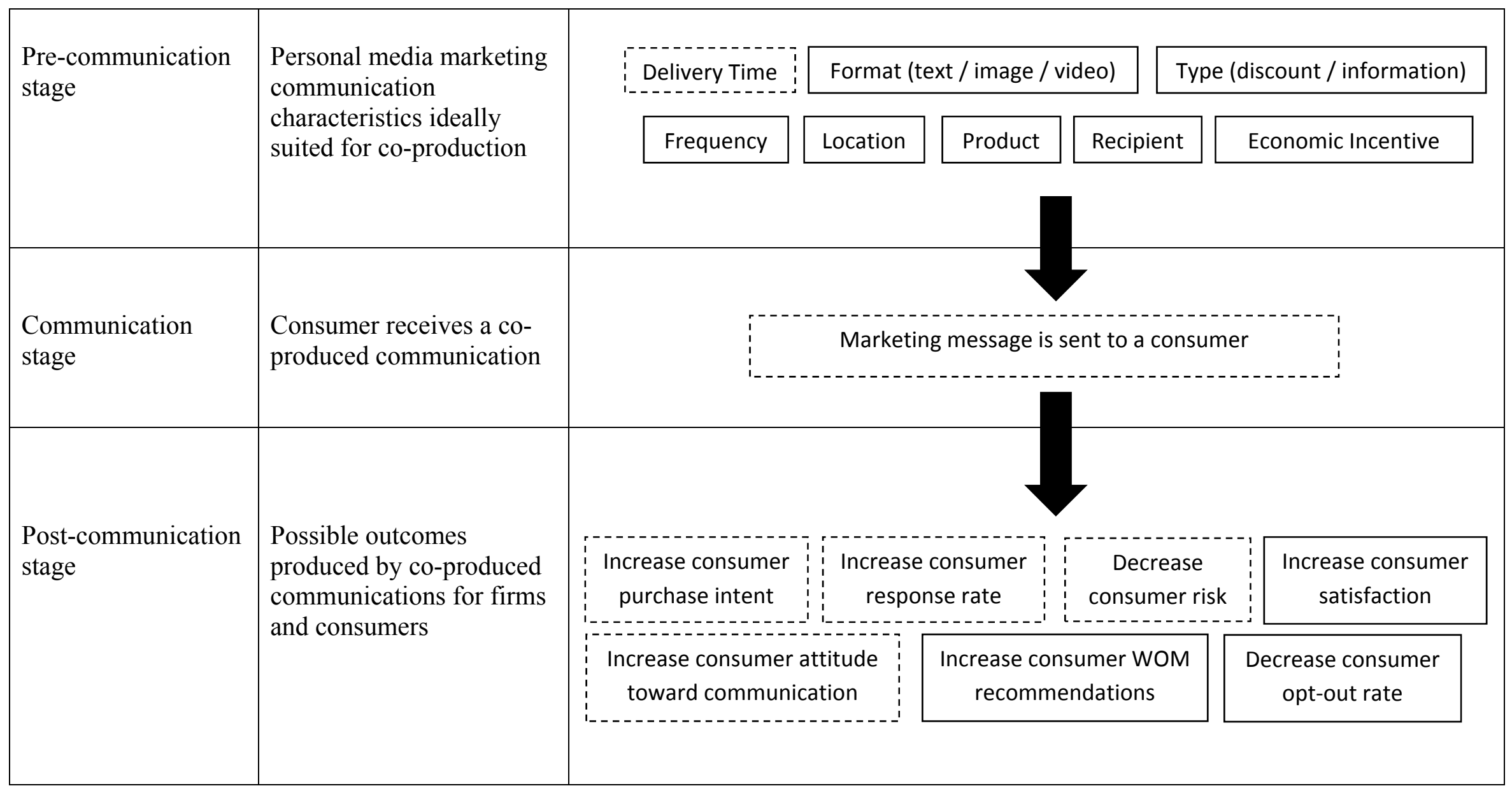

Note: dotted boxes were featured as part of the empirical assessment in the current paper's Study 1 and Study 2. 